\title{
Effects of Propranolol in Accelerating Wound Healing and Attenuation of Hypermetabolism in Adult Burn Patients
}

\author{
Saeed Ashraf Cheema, Urwa Tanveer Ahmed, Hafsa Nasir, Shumaila Rehman Dogar and Zunaisra Mustafa \\ Department of Plastic Surgery, Allied Burn and Reconstructive Surgery Center, Faisalabad, Pakistan
}

\begin{abstract}
Objective: To compare the mean duration of wound healing and attenuation of muscle wasting in adult burn patients treated with propranolol and control group.

Study Design: A randomised controlled trial.

Place and Duration of Study: Allied Burn and Reconstructive Surgery Center, Faisalabad from March to August 2018. Methodology: Seventy adult burn patients with $20-40 \%$ burn of the total body surface area (TBSA) were included in the study and divided into two groups; propranolol group and control group. Propranolol was administered at dose of $0.5-3 \mathrm{mg} / \mathrm{Kg}$ body weight per day along with standard burn care treatment during the entire period of treatment.

Results: Faster healing of the superficial burns was noticed in the patients of propranolol group. In superficial burns lesser time was needed for adequate healing; $13.20 \pm 1.90$ days versus $20.34 \pm 2.32$ days $(p<0.001)$. At the same time, lesser time was required for deep burn patients treated with propranolol to be ready for skin grafting; $23.87 \pm 2.36$ versus 33.64 \pm 3.15 days; $p<0.001$ ) comparing control group. Mean mid-arm circumference was $27.57 \pm 1.62 \mathrm{~cm}$ in study group and $24.46 \pm 1.77 \mathrm{~cm}$ in control group $(p<0.0001)$ which was statistically significant. This result showed that hypermetabolic response of burn in terms of muscle wasting was clearly modulated by betablocker therapy.

Conclusion: Propranolol administration in adult burn patients appears to be beneficial in reducing morbidity, mortality and hospital stay by enhancing earlier wound healing and attenuating the catabolic muscle wasting in response to stress caused by burn.
\end{abstract}

Key Words: Burn injury, Propranolol, Hypermetabolism, Adults.

How to cite this article: Cheema SA, Ahmed UT, Nasir H, Dogar SR, Mustafa Z. Effects of propranolol in accelerating wound healing and attenuation of hypermetabolism in adult burn patients. J Coll Physicians Surg Pak 2020; 30(1):46-50.

\section{INTRODUCTION}

Burn injuries are among the severe injuries with approximately $90 \%$ of cases occurring in low- and middleincome countries. ${ }^{1}$ Thermal injury is a devastating injury that results in a number of pathological alterations in almost every system of the body. Hypermetabolism, muscle wasting, depressed immunity, and impaired wound healing are all clinical features of burns. Failure to address each of these specific pathological alterations can lead to increased mortality. 2 This pathophysiological response to burn injury disturbs the balance between skeletal muscle protein synthesis and breakdown, resulting in severe muscle wasting. Consequently, mitigation of this catabolic response has become a focus in the management of these patients. ${ }^{3}$

Severe thermal injury, defined as burns involving over $20 \%$ of a patient's total body surface area (TBSA), is followed by a pronounced hyper metabolic response that may last up to 1-2 years post-burn. 4 Burn-induced stress

Correspondence to: Prof. Dr. Saeed Ashraf Cheema, Department of Plastic Surgery, Allied Burn and Reconstructive Surgery

Center, Faisalabad, Pakistan

E-mail: sacheema2002@yahoo.com

Received: May 14, 2019; Revised: November 26, 2019;

Accepted: November 26, 2019 response stimulates secretion of endogenous catecholamines, which are thought to be primary mediators of hypermetabolism after stress due to injury. ${ }^{5}$ Propranolol is one of the most extensively studied beta-adrenergic receptor antagonists having strong propensity towards the reduction of post-burn hypermetabolic response. Role of beta-blockers has been demonstrated in numerous studies on adolescent and pediatric age groups.5-7 However, the efficacy of propranolol is not extensively studied in adult burns. ${ }^{8}$

For adults, the incidence of burn is low until the 30 s, with cases occurring at home, outdoors, and at workplaces in equal proportions. ${ }^{9}$ Burn injuries rank the top 15 leading causes of burden of disease globally. 10 Burns which encompass greater than $20 \%$ total body surface area (TBSA) are characterised by pathophysiological stress, insulin resistance, hyperglycemia and catabolism due to factors such as enhanced glycolysis, proteolysis, lipolysis and wasted substrate cycling. ${ }^{11-13}$ Beta blockers are safe and efficient drugs in burn management, which can be included in the basic burn treatment protocol. They counteract the effects of catecholamines, reduce infection and inflammation, thus reducing morbidity and eventually improving the long-term outcome of burn patients. ${ }^{14}$

The safety and efficacy of propranolol in adults is less well established than in children. Adults do not tolerate higher doses reported in pediatric population. ${ }^{15}$ 
This study was conducted to establish the effectiveness of propranolol in adult burn patients in terms of accelerated wound healing and suppression of hypermetabolism for which data is lacking.

\section{METHODOLOGY}

This trial was conducted at Allied Burn and Reconstructive Surgery Center, Faisalabad from March to August 2018. Prior approval was obtained from the Ethical Committee of the Allied Hospital, Faisalabad. Patients fulfilling the inclusion criteria were enrolled in the study and Informed Consents were taken after explaining benefits of propranolol therapy to the patients. Adults with acute burn injuries greater than $20 \%$ TBSA were eligible for propranolol, with exclusion for documented allergies, cardiovascular or pulmonary contraindications to beta-blockers, pregnancy, asthma, peripheral arterial disease, inhalational burns, electrical burns, diabetic patients or patients with persistent hypotension during burn resuscitation.

A standard protocol of administering propranolol was followed throughout the study and patients were carefully observed. The initial propranolol dose was adjusted according to weight of the patient as to achieve a $20 \%$ reduction in maximum heart rate. Propranolol was started on the 3 rd post-burn day after stabilisation of hemodynamic status of the patients.

Propranolol was started at dose of $0.5-1.5 \mathrm{mg} / \mathrm{kg}$ body weight per day, maximum dose upto $3 \mathrm{mg} / \mathrm{kg}$ per day along with standard burn care treatment. Adequate analgesia and similar external environment were given to all the patients and adequate feeding was also given to meet the individual's caloric requirements. Pulse and blood pressure record was maintained 4 hourly. In case of bradycardia (pulse $<60 / \mathrm{min}$ ) and hypotension (B.P $<90 / 60$ ), dose was withheld and started with half of the strength of previous dose after 16 hours then titrated back to the same dose after 48 hours. The study was stopped on patients who showed features of hypersensitivity, respiratory distress or increased morbidity. All the information was recorded on proforma accordingly and results were assessed on various clinical and laboratory parameters. A flowchart of patient selection for the study is shown in Figure 1.

All the data are presented as mean \pm SD (Standard Deviation). Unpaired t-test analysis was employed to compare between control and treatments groups. InVivoStat software (Cambridge, United Kingdom) was used for statistical analysis. ${ }^{16}$ The $p<0.05$ was considered as the statistically significant level.

\section{RESULTS}

Patients with thermal injuries (flame burns, chemical burns and scald burns) were included in the study; total 70 burn patients having $20-40 \%$ burn of TBSA were studied. Patients were divided into two groups: propranolol group and control group (Propranolol group; $\mathrm{n}=35$ and control group; $\mathrm{n}=35$ ) with ages ranging from 18 to 60 years. Different variables characterising the faster burn healing and those showing hypermetabolism for both groups were chosen and results were assessed. Table I shows the characteristics of patients in the two study groups.

Mean mid-arm circumference measured at the start of propranolol therapy was $27.17 \pm 1.76 \mathrm{~cm}$ in study group and $27.29 \pm 1.67 \mathrm{~cm}$ in control group, which was not significant, while at the time of discharge from hospital mean mid-arm circumference was $27.57 \pm 1.62 \mathrm{~cm}$ in study group and $24.46 \pm 1.77 \mathrm{~cm}$ in control group $p<0.001$, which was statistically significant. This statistically significant result showed that hypermetabolic response of burn patients in terms of muscle wasting was clearly modulated by beta-blocker therapy.

Faster healing of the superficial burns was noticed in the patients of propranolol group, (13.20 \pm 1.90 days versus $20.34 \pm 2.32$ days), $p<0.001$ (Figure 2). Less time was required for deep burn patients treated with propranolol to be ready for skin grafting $(23.87 \pm 2.36$ days in propranolol group versus $33.64 \pm 3.15$ days in control group, $p<0.001$ ).

Patients in propranolol group had a shorter hospital stay i.e, $26.69 \pm 3.58$ days as compared to control group with $37.71 \pm 3.68$ days, which was statistically significant $(p<0.001)$.

\section{DISCUSSION}

Propranolol is a nonselective beta-adrenergic antagonist that attenuates the catecholamine response to burn injury. More than $90 \%$ of oral propranolol is absorbed and undergoes extensive first-pass hepatic metabolism. Wide individual variation exists in bioavailability, plasma concentration and half-life. ${ }^{17}$ Common adverse effects of propranolol include hypotension, bradycardia, and hypoglycemia.

It has been shown that propranolol attenuates hypermetabolism and reduces increased incidence of infection and sepsis in severely burned patients. ${ }^{18}$ Early wound contraction and re-epithelisation by the administration of propranolol has been demonstrated in a study which has also shown that there is increase in mast cell migration, polymorphonuclear migration, proliferation of connective tissue and epithelial cells, and angiogenesis by propranolol administration. 19 On the other hand, it reduces the hydroxyproline levels and density of collagen. In addition, further increase in myofibroblastic differentiation and a delay in wound contraction were also observed in the propranolol treated group of rats compared with that of the control group. $20 \beta$-adrenergic receptors are found widely in cutaneous fibroblasts, keratinocytes and endothelial cells. Pullar and collea- 
gues reviewed the effects of $\beta 2$-adrenergic receptor modulation on wound repair and reported modulatory effects on cell proliferation and migration via galvanotaxis, inflammation via neutrophil chemotaxis, wound contraction and re-epithelialisation via kertinocyte migration and fibroblast mediation and angiogenesis via cyclic AMP mediated vascular endo-thelial growth factor expression. 21 In fact, $\beta 2$-adrenergic receptor inhibition in a murine model resulted in increased dermal fibroblast function and re-epithelialisation during the early stages of wound repair.22

Propranolol significantly reduced the time between grafting surgeries by one week, on average. This data is consistent with results from a study of 79 Iranian patients with moderate burn injury (approximately 30\% TBSA burns) in which propranolol improved healing of both partial and full thickness burns. ${ }^{6}$ Indeed, this study showed that wound surface that finally needed skin graft was smaller; and faster healing time was observed in propranolol group as compared to control group.

Prevention of wound infection, attenuation of hypermetabolic state, and preservation of protein stores are potential benefits of propranolol administration which may be the major reasons for wound size reduction and improvement in wound healing.

The effects of treatment on the net balance of muscle protein synthesis and breakdown during propranolol administration have been demonstrated earlier. ${ }^{23}$ In this study, anabolism was achieved and the protein net balance was significantly greater after treatment with propranolol than in the untreated patients. A study by Gore et al. provided evidence that propranolol administration significantly reduces peripheral perfusion via increased leg resistance in adults with severe burn

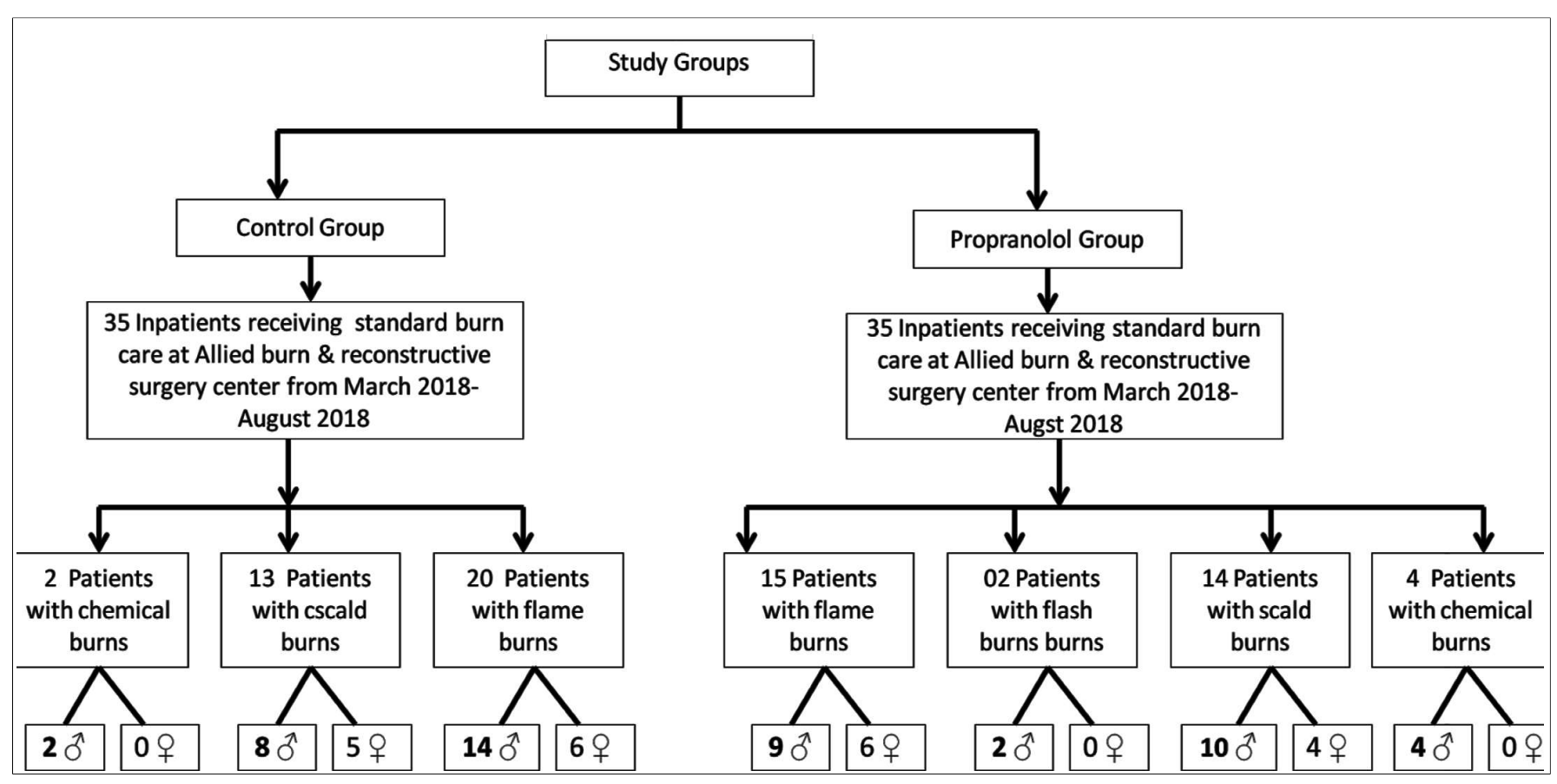

Figure 1: Flowchart of selection criteria of patients included in the study

Table I: Characteristics of patients in two study groups.

\begin{tabular}{|c|c|c|c|}
\hline Variable & Propranolol group & Control group & $\mathrm{p}$-value \\
\hline Mean burn size (TBSA \%)* & $28.66 \pm 4.39$ & $28 \pm 3.89$ & .579 \\
\hline Mean third-degree burn size (TBSA \%) ${ }^{*}$ & $10.82 \pm 4.69$ & $14.24 \pm 4.89$ & .023 \\
\hline Mean second-degree burn size (TBSA \%)* & $17.91 \pm 5.14$ & $13.79 \pm 4.84$ & 0072 \\
\hline Mean heart rate (beat/min) & $76.17 \pm 5.32 \dagger$ & $103.29 \pm 5.48$ & $<.0001$ \\
\hline Mean mid-arm circumference $(\mathrm{cm})$ at day 1 & $27.17 \pm 1.76$ & $27.29 \pm 1.67$ & .8333 \\
\hline Mean mid-arm circumference $(\mathrm{cm})^{\star *}$ & $27.57 \pm 1.62$ & $24.46 \pm 1.77$ & $<.0001$ \\
\hline Mean weight $(\mathrm{Kg})$ at day 1 & $67.97 \pm 8.95$ & $68.43 \pm 8.61$ & .849 \\
\hline Mean weight $(\mathrm{Kg})^{\star *}$ & $68.69 \pm 9.07$ & $66.20 \pm 8.26$ & .299 \\
\hline Healing time $(\mathrm{d})$ & $13.20 \pm 1.90$ & $20.34 \pm 2.32$ & $<.0001$ \\
\hline Time ready for graft $(\mathrm{d})$ & $23.87 \pm 2.36$ & $33.64 \pm 3.15$ & $<.0001$ \\
\hline Area needed skin graft (TBSA \%) & $10.09 \pm 5.33$ & $13.15 \pm 5.10$ & .0429 \\
\hline Albumin infused (g/dl) & $292.60 \pm 36.89$ & $382.74 \pm 53.39$ & $<.0001$ \\
\hline Hospital stay period (days) & $26.69 \pm 3.58$ & $37.71 \pm 3.68$ & $<.0001$ \\
\hline
\end{tabular}

*Estimated by the surgeon on the 7th day of admission; †After propranolol prescription; ** At discharge from hospital. 


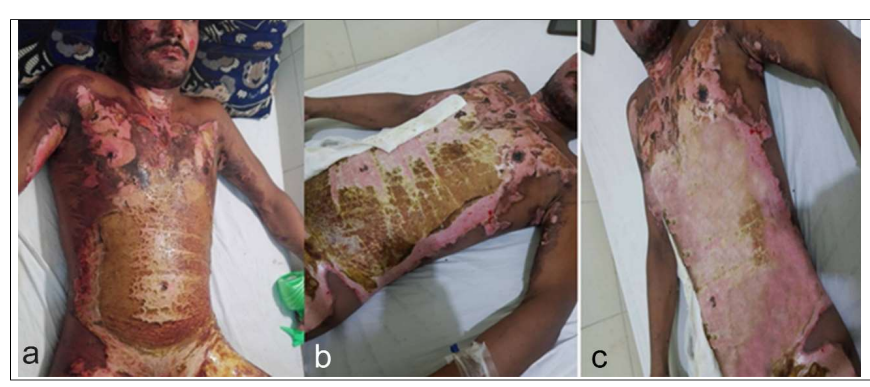

Figure 2: A 29-year labourer presented with second degree scald burn mostly superficial partial thickness: (a) $3^{\text {rd }}$ post-burn day, (b) $7^{\text {th }}$ post-burn day, (c) $11^{\text {th }}$ post-burn day.

injury. ${ }^{24}$ They observed a reduction in arterial and venous lactate levels in both burned and nonburned adults following two hours of intravenous propranolol administration. Beta blockade was thought to have reduced lactate production via inhibition of lipolysis. 24

Preservation of protein and amino-acid stores and inhibition of lipolysis seems to be crucial for regeneration of epithelial cells and granulation tissue formation, as well as inhibit mobilisation of body stores of these essential building blocks in response to severe trauma by burn. Thus stability of muscle proteins provided by beta blockade therapy resulted in preservation of muscle mass and maintenance of weight of the patients. This study has shown this modulatory effect of propranolol in attenuating hypermetabolic state and decreasing muscle wasting.

In the present study, we have found that propranolol improved healing process, decreased duration of wound healing (shorter time from admission to acceptable wound healing). Moreover, there was reduction in wound size and no muscle wasting was observed in propranolol group. Patients in propranolol group had a shorter hospital stay than control group, although more clinical trials should be performed on these variables in future.

\section{CONCLUSION}

Beta adrenergic antagonist treatment using propranolol in adult burn patients appears to be beneficial in reducing morbidity, mortality and hospital stay. It reduces morbidity by enhancing earlier wound healing and attenuating the hypermetabolic response of body after stress by burn. Higher propranolol dosages are less tolerated by previously normotensive patients and result in multiple episodes of hypotension. Bradycardia was observed less often than hypotension.

\section{ETHICAL APPROVAL:}

Prior approval was obtained from the Ethical Committee of the Allied Hospital, Faisalabad.

\section{PATIENTS' CONSENT:}

Informed consents were taken after explaining benefits of propranolol therapy to the patients.

\section{CONFLICT OF INTEREST:}

Authors declared no conflict of interest.

\section{AUTHORS' CONTRIBUTION:}

SAC: Conception and design of work, revising it critically, final approval to be accountable for all aspects of work UTA, HN, SRD, ZM: Acquisition, analysis or interpretation of data, drafting, final approval, agreement to be accountable for all aspects of work.

\section{REFERENCES}

1. Manzano-Nunez R, García-Perdomo HA, Ferrada P, Ordoñez Delgado CA, Gomez DA, Foianini JE. Safety and effectiveness of propranolol in severely burned patients systematic review and meta-analysis. World J Emerg Surg 2017; 12:11.

2. Abdullahi A, Jeschke MG. Nutrition and anabolic pharmacotherapies in the care of burn patients. Nutr Clin Pract 2014; 29:621-30.

3. Diaz EC, Herndon DN, Porter C, Sidossis LS, Suman OE, Børsheim $\mathrm{E}$, et al. Effects of pharmacological interventions on muscle protein synthesis and breakdown in recovery from burns. Burns 2015; 41:649-57.

4. Garrel D, Patenaude J, Nedelec B, Samson L, Dorais J, Champoux J, et al. Decreased mortality and infectious morbidity in adult burn patients given enteral glutamine supplements a prospective controlled randomized clinical trial. Crit Care Med 2003; 31:2444-9.

5. Barret JP, Jeschke MG, Herndon DN. Fatty infiltration of the liver in severely burned pediatric patients autopsy findings and clinical implications. J Trauma 2001; 51:736-9.

6. Mohammadi AA, Bakhshaeekia A, Alibeigi P, Hasheminasab MJ, Tolide-ei HR, Tavakkolian AR, et al. Efficacy of propranolol in wound healing for hospitalized burn patients. J Burn Care Res 2009; 30:1013-7.

7. Herndon DN, Rodriguez NA, Diaz EC, Hegde S, Jennings K, Mlcak RP, et al. Long-term propranolol use in severely burned pediatric patients: A randomized controlled study. Ann Surg 2012; 256:402-11.

8. Arbabi S, Ahrns KS, Wahl WL, Hemmila MR, Wang SC, Brandt MM, et al. Beta-blocker use is associated with improved outcomes in adult burn patients. J Trauma 2004; 56:265-9.

9. Forjuoh SN. Burns in low and middle-income countries: A review of available literature on descriptive epidemiology risk factors treatment and prevention. Burns 2006; 32:529-37.

10. Burton KR, Sharma VK, Harrop R, Lindsay R. A populationbased study of the epidemiology of acute adult burn injuries in the Calgary health region and factors associated with mortality and hospital length of stay from 1995 to 2004. Burns 2009; 35:572-9.

11. Hart DW, Wolf SE, Chinkes DL, Gore DC, Mlcak RP, Beauford RB, et al. Determinants of skeletal muscle catabolism after severe burn annals of surgery. Ann Surg 2000; 232:455-65.

12. Jeschke MG, Chinkes DL, Finnerty CC, Kulp G, Suman OE, Norbury WB, et al. Pathophysiologic response to severe burn injury annals of surgery. Ann Surg 2008; 248:387-401.

13. Yu YM, Tompkins RG, Ryan CM, Young VR. The metabolic basis of the increase in energy expenditure in severely burned patients. JPEN J Parenter Enteral Nutr 1999; 23:160-8. 
14. Lunawat A, Vishwani A, Datey S, Singh V. Modulation of hypermetabolism in burn patient by administration of propranolol in the first two weeks and assessing its effect by using clinical and biochemical parameters. Indian J Burns 2015; 23:19-25.

15. Gibbons J, Honari S, Klein MB, Pham TN, Gibran NS. Propranolol dosing practices in adult burn patients implications for safety and efficacy. J Burn Care Res 2016; 37:e218-26.

16. Ali HM, Qureshi AS, Hussain R, Urbinati G, Mustafa MZ, Ali F, et al. Effects of natural environment on reproductive histomorphometric dynamics of female dromedary camel. Anim Reprod Sci 2017; 181:30-40.

17. Herndon DN, Barrow RE, Rutan TC, Minifee P, Jahoor F, Wolfe RR. Effect of propranolol administration on hemodynamic and metabolic responses of burned pediatric patients. Ann Surg 1988; 208:484-92.

18. Jeschke MG, Norbury WB, Finnerty CC, Branski LK, Herndon DN. Propranolol does not increase inflammation, sepsis, or infectious episodes in severely burned children. J Trauma 2007; 62:676-81.

19. Ali A, Herndon DN, Mamachen A, Hasan S, Andersen CR,
Grogans RJ, et al. Propranolol attenuates hemorrhage and accelerates wound healing in severely burned adults. Crit Care 2015; 19:217.

20. Souza BR, Santos JS, Costa AM. Blockade of beta 1 and beta 2 adrenoceptors delays wound contraction and reepithelialization in rats. Clin Exp Pharmacol Physiol 2006; 33: 421-30.

21. Pullar CE, Manabat Hidalgo CG, Bolaji RS, Isseroff RR. Betaadrenergic receptor modulation of wound repair. Pharmacol Res 2008; 58:158-64.

22. Pullar CE, Le Provost GS, O'Leary AP, Evans SE, Baier BS, Isseroff RR. Beta 2AR antagonists and beta 2AR gene deletion both promote skin wound repair processes. $J$ Invest Dermatol 2012; 132:2076-84.

23. Hart DW, Wolfe SE, Chinkes DL, Lal SO, Ramzy PI, Herndon DN. Beta-blockade and growth hormone after burn. Ann Surg 2002; 236:450-6.

24. Gore DC, Honeycutt D, Jahoor F, Barrow RE, Wolfe RR, Herndon DN. Propranolol diminishes extremity blood flow in burned patients. Ann Surg 1991; 213:568-73. 